CATALAN REVIEW

Catalan Review

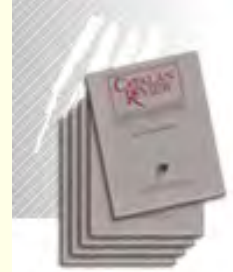

You are accessing the Digital Archive of the Catalan Review Journal.

By accessing and/or using this Digital Archive, you accept and agree to abide by the Terms and Conditions of Use available at http://www.nacs-

catalanstudies.org/catalan review.html

Catalan Review is the premier international scholarly journal devoted to all aspects of Catalan culture. By Catalan culture is understood all manifestations of intellectual and artistic life produced in the Catalan language or in the geographical areas where Catalan is spoken. Catalan Review has been in publication since 1986.
NORTH

AMERICAN

CATALAN

SOCIETY
Esteu accedint a l'Arxiu Digital del Catalan Review

A l' accedir i / o utilitzar aquest Arxiu Digital, vostè accepta i es compromet a complir els termes i condicions d'ús disponibles a http://www.nacs-

catalanstudies.org/catalan review.html

Catalan Review és la primera revista internacional dedicada a tots els aspectes de la cultura catalana. Per la cultura catalana s'entén totes les manifestacions de la vida intel lectual i artística produïda en llengua catalana o en les zones geogràfiques on es parla català. Catalan Review es publica des de 1986.

\title{
Tres poemes de Josep Carner Manuel Duran
}

Catalan Review, Vol. XVI, number 1-2, (2002), p. 133-139 


\section{TRES POEMES DE JOSEP CARNER}

\section{MANUEL DURAN}

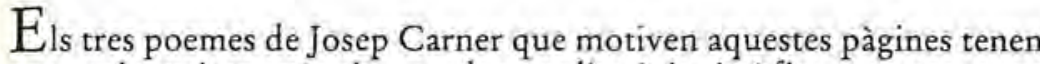
per a mi una importància no solament literària sinó fins a un cert punt sentimental i emocional, ja que els vaig escoltar, en versió preliminar, dels llavis del poeta, en aquells anys incerts i turbulents del nostre exili en terres mexicanes.

Els tres poemes ens permeten endinsar-nos en el pensament del poeta, i representen punts de vista diferents, fins i tot oposats o contradictoris. Hi trobem un Carner enamorat de la natura, els arbres, les flors, la bellesa femenina i, d'altra banda, un poeta conscient que l'horitzó de la seva vida s'ha tornat fosc, difícil, ple d'angoixa. A Mèxic, Carner escriu un llibre de poemes titulat $A$ bsència, que quedarà molts anys inèdit. El títol és significatiu. Enyorança, idealització d'una Catalunya absent de la seva vida d'exiliat, una pàtria aclaparada per la dictadura franquista. Fins i tot el poeta té el trist pressentiment que morirà a l'exili, que hauran de passar molts anys abans que Catalunya pugui recuperar la llibertat i les il-lusions perdudes. El primer poema d'aquest llibre, "De lluny estant", crea en els dos versos finals un ambient de tristesa i desconhort:

En mos camins d'un temps, hom po: trobar-hi

un àngel trist amb el seu glavi tort. (I: 861)

Joan Fuster, un dels millors crítics de la nostra literatura, comenta:

Quan acaba la guerra civil, Josep Carner ré 55 anys. Tot s'ensorra aleshores: les il-lusions noucentistes que encara li podien quedar, el seu país a mig restaurar, la convenció d'una societat perdurable $\mathrm{i}$ còmoda... un altre Carner se sobreposa al Carner anterior: un Carner llatzerat per les circumstàncies i per la vida, més meditatiu i reconcentrat, que posa en els seus versos un tremolor inèdit, conceptual o sentimental, patit en la seva aventura d'home més que en els seus càlculs d'escriptor, (178)

La crisi de la guerra i la desfeta de la República i de l'Estatut català és la tragèdia que fa canviar de direcció la poesia de Carner i, puc afegir, el mateix fenomen es pot constatar a les Elegies de Bierville de Carles Riba. Encara tinc un record molt concret, molt viu, de Carles Riba, que va conviure amb la meva família, i va compartir amb nosaltres i la família Surribes la mateixa casa a Montpeller, a la França de Vichy, durant mesos d'aquells anys terribles. El Riba que escoltava cada nit totes les emissores de ràdio d'Europa i algunes d'Amèrica ho 
creia tot perdut; opinava que sense cap mena de dubte els exèrcits de Hitler havien guanyat la guerra. Els escriptors en llengua catalana, els catalans tots en conjunt, no podrien mantenir les tradicions culturals que ens havien donat la nostra identitat. Creia que la cultura catalana patiria la mateixa sort que la cultura medieval provençal: tot el que es podria salvar seria una cultura de museu, limitada a un molt petit nombre de "felibres", arqueòlegs d'una tradició perduda.

No era aquesta l'opinió de Carner, i el llarg poema Nabi és una prova irrefutable que la seva actitud era molt més esperançada i optimista, fins i tot heroica. Ara bé, no voldria pas criticar l'actitud de Carles Riba, i de la seva muller, Clementina Arderiu, que compartia amb el seu marit el pessimisme més extrem. Nosaltres, a la França de Vichy, estàvem contínuament sota la vigilància de la policia del mariscal Pétain, que interrogava sovint els refugiats i, tràgicament, els entregava, com va ser el trist cas del nostre President, Lluís Companys, que va passar de la policia francesa a la Gestapo i de la Gestapo a la policia franquista, $i$ com sabem tots va ser salvatgement torturat $i$ afusellat a Montjuic. El clima de la França on viviem nosaltres, els Riba i la meva família, amb centenars de milers d'altres refugiats, era molt diferent del clima de Mèxic, on va arribar Carner amb un dels primers vaixells que portaren els refugiats catalans a l'altra banda de l'Atlàntic. i on vaig arribar jo el 1942.

Malgrat aquestes diferències, és evident que l'experiència de l'exili hauria de produir una fonda impressió en la poesia dels catalans d'aquells anys. Tant Màrius Torres com Salvador Espriu van viure l'exili des de dins de Catalunya, l'anomenat exili interior. Carner, Riba, Bartra i tants d'altres escriptors van viure l'exili exterior. Quin dels dos exilis va ser el més trist, el més tràgic, seria un tema molt difícil de tractar. Més fàcil resultaria comparar la reacció davant l'exili de Carner, amb el seu important poema $N a b i$, amb la reacció al mateix exili de Riba, amb les seves Elegies de Bierville. És possible detectar, en ambdós poemes, una actitud religiosa, o almenys afectada per sentiments profunds que solem associar amb la religió, o potser amb una filosofia existencial no molt diferent de l'actitud religiosa. És aquest un tema que penso tractar molt aviat.

Ara em limitaré a assenyalar i comentar tres poemes de Josep Carner que corresponen a aquest llarg període de la vida del poeta, els anys passats fora d'una Catalunya aclaparada per la dictadura franquista, i que em semblen resumir la vida interior del poeta durant aquells anys.

El primer, trist, adolorit, ple de melangia. El segon, un himne a la bellesa del món natural que ha estat una constant en la poesia de Carner a partir de Els fruits saborosos. Finalment, un poema molt original i molt simpàtic, una recreació de la història de Mèxic evocada per 
un arbre florit, la famosa "Xicranda de Mèxic", poema ple de bonhomia i d'una ironia tendra que ens recorda que, en efecte, la ironia és un dels millors recursos estilístics del nostre poeta.

Aquests tres poemes em permeten arribar a la conclusió que, en realitat, Carner presentava al públic una actitud optimista, plena de confiança en el futur, mentre íntimament estava preocupat $i$ pessimista. A molts dels catalans de Mèxic ens semblava que Carner havia assolit una situació envejable, amb més prestigi i més influència que la major part dels exiliats, i que se sentia relativament còmode. Ell, d'altra banda, escrivia:

Terra d'atzar, indiferent xopluc,
i tu, cansada i erta llunyania,
guerra, menant els corbs a confraria,
mort, amb els teus alans sense lladruc $[\ldots]$. (I: 875 )

No sabem amb precisió si el vers "i tu, cansada i erta llunyania" es refereix a la Catalunya de la trista postguerra franquista o bé a tota l'Europa occidental dominada pel nazisme i el feixisme. L'efecte pessimista és, de totes maneres, ben evident. Albert Manent comenta: "Tanmateix, la desesperació no desola cap poema: un capteniment melangiós, una tristesa que no sanglota, limiten els ecos dramàtics. I barrejant-se amb el sentiment del món esfondrat, el deler del retorn, de vegades mig confessat, d'altres esclatant, i amb la temença d'una tornada impossible” (I46). Típic d'aquells anys difícils del començament del llarg exili és el poema "Si cal que encara et vegi":

Si cal que encara et vegi, lloc meu i fe primera,

que sigui un dia de tardor i a seny d'estels,

i el llaurador, fet ombra, hagi deixat enrera

la plana ben escrita de versos paral-lels.

I en l'agombol del vespre, que alguna veu molt pura

desgrani la tonada que el meu bressol oí

abans que sense termes i sense afegidura

no negui mes parpelles la nit d'on vaig eixir. (I: 866)

Malgrat tot, els anys passats a Mèxic havien de deixar una empremta en part positiva en la poesia carneriana. L'any 1953 apareix el llibre Arbres, en el qual figura un poema inspirat per un arbre típicament mexicà, una xicranda o bé "Jacaranda". N'he vist també a la Florida, perô són arbres importats de Mèxic. Molts carrers de la ciutat de Mèxic queden cada primavera decorats per les flors de les xicrandes, d'un color entre blau i morat, summament atractiu. El poema es titula precisament "Xicranda de Mèxic", i comença així: 
Una xicranda florida

enlluerna tot el món.

Flama fosca de la terra

que amb color de cel es fon [...]. (I: 528)

El poema és expansiu. Passa de la visió d'un sol arbre a un enlluernament col-lectiu, i combina els colors de la terra i el cel, recordant aixi que el color predominant de les flors és el blau, encara que un matís molt especial de blau. La sinestèsia domina els següents quatre versos:

\author{
Música es tornà la saba \\ com d'un innombrable amor; \\ resseguí tot el fustatge \\ el do liquid i sonor. (I: 528 )
}

La pujada de la saba a la primavera és el que fa possible les noves fulles verdes i després les flors. El poeta creu escoltar aquesta saba que puja pel tronc i després les branques, com una música:

El goig que en la rel arpègia

dins de li soca retruny;

hi concerta una esperança

la fullada, encara lluny. (I: 528 )

Les paraules referents a la música (arpegi, concert) ens fan veure l'arbre com un instrument musical que comença a vibrar a les arrels i més tard (encara lluny) la música es transformarà en fulles verdes.

Finalment la sinestèsia es transforma en miracle: saba, fulles i flors, produiran una mena d'explosió, un incendi de color i de música:

I tors junts, en llur miracle

-so i color que hi equival-

traspassen a un musc incendi

llur gran acord triomfal. (I: 528 )

El tercer poema que voldria comentar, inspirat també pel seu temps d'exili a Mèxic, és interessant com a comentari psicològic, històric i dramàtic. Es, també, un poema construit en torn d'un arbre, una vegada més el famós arbre mexicà, la xicranda. I, sobretot, és un poema suaument irònic.

En un pròleg al llibre de Francesc Trabal, L'any que ve, Carner assenyalava que el mal dels catalans és que som obvis; només la ironia és capaç de desvetllar-nos de l'estupidesa que comporta veure-ho tot clar i a través d'un sentit comú, d'un seny, de curta volada. Cal que no oblidem mai, insinua el poeta, que sobre tots nosaltres plana l'esperit 
del senyor Esteve, el de la famosa auca de Santiago Rusiñol, amb el seu somrís superficial i sinistre al mateix temps; com indicava fa poc Bernat Puigtobella, "el poeta advocava per la ironia com a única arma capaç de superar aquest atavisme català que s'imposa fins als nostres dies $i$ que avui dia encara retrobem, a cada cantonada, quan sentim dir coses de l'estil 'ja som al cap del carrer', 'demà serà un altre dia', 'ciutadans, ja sóc aquî o 'som 6 milions" (130). "L'obvi, doncs, hauria dit Carner, és l'autèntic opi del poble català; limitant-nos a corroborar amb paraules el que tenim davant dels nassos no arribarem a qüestionar-nos res de debò ni traurem l'entrellat de qui som; d'això, Calders sembla haver-ne pres bona nota quan diu que per a ell la literatura consisteix a buscar altres noms a les coses" (Puigtobella 130).

Ironia i caricatura ens portaran molt més lluny. Ara bé: aquesta ironia que podriem qualificar d'ironia pedagògica, tan típica de Carner, també es pot aplicar a altres cultures. Al poema "Xicrandes fullades", el poeta fa un resum de la història de Mèxic des de la conquesta fins a les darreries del segle XIX i el modernisme poètic i artístic:

Xicranda, fulles de randa, trèmules de cent albirs, amb un calat per als somnis

i amb un serrell de sospirs. (1: 529)

Ja establert aquest paisatge vegetal, comença la narració:

Tal volta d'una xicranda recerant-se a l'afalac, una molt gerda princısa de pits color de tabac,

parladora en refilades, dels ocells amb entenent, i que en els seus ulls tenia dolceses de sol ponent,

caigué, primera de totes, vora un florit devessall, als braços d'un home pàl-lid que duia espasa i capmall. (I: 529)

Aixi s'inicia el mestissatge, origen del Mèxic d'avui. Ara passem a la guerra de la Independència iniciada per Hidalgo i Morelos:

Portat vora una xicranda defallí un tinent crioll, amb el rull d'una casada i un escapulari al coll, 
per una bala d'Espanya

espiat i malferit;

quan a l'ombra del capvespre

ja retia l'esperit [...] (I: 529)

I finalment el contrast irònic i còmic: un pobre buròcrata voltat dels seus nens que criden, ploren i tenen fam, però segueix pensant en un París ideal, en una França amb ballarines que porten blancs tutús, $i$ on es beu absenta: l'evocació aquí inclou un quadre de Manet, "L'Absinthe", i molts quadres de Degas amb ballarines amb tutús, imatges glorioses d l'art del segle dinou, en viu contrast amb el pobre, fins i tot famèlic present del buròcrata mexicà:

I al ventall d'altra xicrandra

un mestís desavinent, en son temps oficinista

demagògic $i$ insolvent,

lluny dels crits d'una mainada

sempre en lluita, sempre en fam,

dels estels i les lluernes

ajagut sota l'eixam,

sospirava al clar de lluna,

un sonet al foll encís

dels tutús de ballarines

i l'absenta de París. (I: 529)

En tres etapes la història de tres segles s'ha projectat com un film molt vell, a sotregades, massa de pressa per veure tots els detalls, alho$\mathrm{ra}$ informatiu $\mathrm{i}$ cồmic. El poema s'assembla a una auca, i té la rigidesa de l'auca i de les millors caricatures. El domini de la llengua catalana per part de Carner és total, absolut, i també la seva penetració psicológica i històrica. Un punt de partida concret, la bellesa de l'arbre mexicà, la xicranda, li ha servit com a trampolí per projectar-se cap a la història i la sociologia, és a dir, per transformar un detall precís, una visió parcial, en un panorama universal.

Només un gran poeta és capaç de produir aquesta transformació. La meva conclusió és, senzillament, que aquests tres poemes de Carner ens mostren que ha estat, és avui i serà demà, un dels grans, inoblidables poetes de la llengua catalana. 


\section{REFERÈNCIES}

CARNER, Josep. Obres Completes. Barcelona: Selecta, 1957.

FUSTER, Joan. Literatura catalana contemporània. Barcelona: Curial, 1972.

MANENT, Albert. Escriptors i editors del Nou-cents. Barcelona: Curial, 1984.

Puigtobella, Bernat. Síndrome d'Estocolm. L'Auca del Nobel. Barcelona: Edicions 62, 200I. 